\title{
Extraction and purification of recombinant intact human Parathyroid Hormone (hPTH) from bacterial cell
}

\author{
Adnan E. Al-badran ${ }^{1}$, Rafeef A. Abdul-jabbar*2 \\ ${ }^{1}$ University of Basra, College of Science, Department of Biology, Basra, Iraq \\ ${ }^{2}$ University of Basra, College of Pharmacy, Department of Clinical Laboratory Science, Basra, Iraq
}

Received: December 31, 2016

Accepted: March 2, 2017

Online Published: March 15, 2017

DOI: $10.5430 /$ jbei.v3n2p1

URL: https://doi.org/10.5430/jbei.v3n2p1

\begin{abstract}
Objective: The intact human Parathyroid hormone (hPTH) is one of the biopharmaceutical drug produced by biotechnology, this hormone can be provided in a good amount using simple batch culture, and therefore the main purpose of this study was the production of purified bioactive intact hPTH.

Methods: A cloning BL21(DE3) strain (which already cloned in our Lab. by synthetic human Parathyroid hormone (shPTH gene) was grown in LB medium and the cloning gene expression was induced by addition of IPTG to the medium. The recombinant fused protein was purified from the bacterial cell lysate by affinity chromatography and underwent proteolysis by Enterokinase enzyme to obtain the target hPTH, and it's further purified by DEAE and SP Sepharose ion exchange chromatography. RPHPLC analysis and biological activity on the MCF-7 breast cancer cells were done for both the standard and produced hPTH. Furthermore, the haemolysis ability of the latter was tested on the human RBC.

Results: $225 \mathrm{ng} / \mathrm{ml}$ of hPTH was produced after SP chromatography which detected by specific PTH ELISA kit, standard and produced hPTH showed the same peaks in the same retention time when analyzed by HPLC. The produced hPTH haemolysis assay showed the ability of the produced $\mathrm{hPTH}$ to partially haemolyze human RBC in a concentration above $200 \mu \mathrm{g} / \mathrm{ml}$. The bioactivity assay for the produced and standard rhPTH demonstrated that both compounds had a biological activity on the MCF-7 cells with IC50 of about 84.4 and $75.7 \mu \mathrm{g} / \mathrm{ml}$ for standard and produced hPTH respectively, and no significant difference was detected between them.

Conclusions: Via suitable purification processes, the biologically active hPTH with structure similar to the standard ones as detected by RP-HPLC and bioactivity assay, can be obtained by using already cloned isolate with $s$ PTH gene for hormone production. The hormone showed haemolysis effect on the RBC similar to the normal secreted hPTH.
\end{abstract}

Key Words: hPTH, Parathyroid hormone, Enterokinase, hPTH haemolysis

\section{INTRODUCTION}

Biopharmaceuticals drugs basically resemble the compounds present within the body and are produced by biotechnologies. These have the ability to cure diseases rather than treat some disease symptoms, and have less side effects due to their specificity, for example clotting factors, vaccines, cytokines, hormones, enzymes, monoclonal antibodies, cell therapies, antisense drugs, and peptide therapeutics. ${ }^{[1]}$ An example

\footnotetext{
* Correspondence: Rafeef A. Abdul-jabbar; Email: rafeefamir@gmail.com; Address: University of Basra, College of Pharmacy, Department of Clinical Laboratory Science, Basra, Iraq. 
of these biopharmaceutical drug is the human parathyroid hormone which is one of the most important proteins, this protein secreted by the chief cells of the Parathyroid gland as a polypeptide containing 84 amino acids. Parathyroid hormone works normally, if Calcium ion concentrations in extracellular fluid fall below normal to bring them back within the normal range. ${ }^{[2]}$ Intermittent low-dose treatment with recombinant human Parathyroid hormone (rhPTH 1-84) or recombinant human PTH peptide 1-34 (teriparatide) were used in the treatment of severe Osteoporosis, Daily injections of Parathyroid hormone (PTH), increase bone mass and reduce the incidence or prevention of Osteoporotic fractures in postmenopausal women, elderly men, and women with glucocorticoid-induced Osteoporosis. ${ }^{[3-5]}$ Administration of PTH by this way result in an increase in the number and activity of Osteoblasts leading to an increase in bone mass and improvement in skeletal architecture at both trabecular and cortical bone. ${ }^{[3]}$ Therefore, from the eighteenth of the last century till now, the attempts to produce the recombinant active parathyroid hormone with full length (84 amino acid) were recurred in verifying hosts, like Escherichia coli, yeast like Hansenula polymorph, Saccharomyces cerevisiae, Pichia pastoris, mammalian cells like Rat Pituitary Cells, Bombyx mori larvae and others using various recombinant vectors that carrying the gene coding for Parathyroid hormone. All these attempts aimed to get a large scale of hormone production with more suitable and simple extraction and purification method and that makes the other important part in the production of the recombinant protein is the processes of extraction and purification of that protein. The purification of the Protein is a combination of several techniques generally used to assure the quantity, quality, and desired purity of the target protein. ${ }^{[6]}$ At the last two decades, the advances in genomics and proteomics made the protein purification more easy for instance, using the affinity tag with the gene of interest can form a fusion gene (therefore, tag is also called a fusion tags) which are then translate to a protein or peptide with a specific properties fused with target protein to improve recombinant protein expression yields, enable protein purification, and accelerate the characterization or analysis of protein structure and function. ${ }^{[7]}$ Examples of present tags are the Histidine, glutathione S-transferase (GST), maltose binding protein (MBP), or Strep-tag ${ }^{\mathrm{TM}}$ II. Tags enable recombinant proteins to be purified by affinity chromatography (AC) which is one of the most diverse and powerful chromatographic methods for purification of a specific molecule or a group of molecules from complex mixtures. ${ }^{[6,8]}$ It is based on highly specific biological interactions between two molecules, such as interactions between enzyme and substrate or antibody and antigen etc. ${ }^{[8]}$ A more com- monly used technique for purifying the recombinant proteins is the liquid chromatography which is based on the principle that molecules dissolved in a solution will interact (bind and dissociate) with a solid surface or beads. If the solution is allowed to flow across the surface, then molecules that interact frequently with the surface will spend more time bound to the surface and thus move more slowly than molecules that interact infrequently with the surface. The nature of these beads determines whether separation of proteins depends on differences in mass, charge, or binding affinity, ${ }^{[9]}$ and that is the main principle for all chromatography, especially those used to achieve the aim of this study which is extraction, purification and characterization of some of the chemical and biological features of the produced recombinant hormone by using simple batch culture.

\section{METHOD}

\section{Cloning strain and Enzyme}

A cloning E. coli strain BL21 (DE3), was used for recombinant $\mathrm{hPTH}$ production. The isolate was transformed in our laboratory by a constructed pET32a-shPTH vector, the latter contain a synthetic human PTH gene fused with (Trx. A) gene, (S-tag and 6xHis tag) nucleotide sequence. The fused gene was under the control of T7 promoter, Enterokinase enzyme was purchased from Invitrogen (USA). LB broth was synthesized by dissolving $10 \mathrm{gm}$ trypton, $10 \mathrm{gm} \mathrm{NaCl}$ and 5 gm yeast extract in 11 of D.W. with $P H=7$. The DEAE and SP sepharose prepacked column supplied from GE health care (UK) and dialysis sac supplied from Bio basic (Canada).

\section{Expression of recombinant (shPTH-Trx A-HisTag) fused gene by the cloning isolates}

The BL21 (DE3) colony which transformed by a constructed pET32a-shPTH inoculated in $5 \mathrm{ml}$ of LB broth and the broth incubated at $37^{\circ} \mathrm{C}$ for overnight, $5 \mathrm{ml}$ of broth used to inoculate $250 \mathrm{ml}$ of LB broth containing $(50 \mu \mathrm{g} / \mathrm{ml})$ Ampicillin in $1 \mathrm{~L}$ flask. The flasks were incubated at $37^{\circ} \mathrm{C}$ with $250 \mathrm{rpm}$ shaking until the OD600 $\mathrm{nm}$ of the culture (cells growth) reached to $(0.8-1.1)$. Then, the broth media was induced for recombinant protein production by addition of IPTG with a final concentration of $1 \mathrm{mM}$, after induction the broths were incubated with $250 \mathrm{rpm}$ shaking at $30^{\circ} \mathrm{C}$ for 4-5 hours. ${ }^{[10]}$ A little volume of the LB broth was taken for calculation of the total bacterial cell protein concentration by using Lowry method, ${ }^{[11]}$ and the whole cells were harvested by centrifugation at $5,000 \mathrm{rpm}$ for 20 minutes.

\section{Microscopic examination of production isolate}

A little volume of production medium was used for microscopic examination of the production isolate by light micro- 
scope and by scanning electron microscope, the examination of the production isolate by scanning electron microscope required a few preparation steps that described by Schädler et al. ${ }^{[12]}$ with a slightly modifications. In this method, the bacteria in $(2 \mathrm{ml})$ of LB production medium were harvested by centrifugation at 5,000 rpm for 3-4 minutes. Then $(1 \mathrm{ml})$ of the chemical fixation sol. $(0.25 \%$ of Glutaraldehyde in phosphate buffer saline [PBS]) was added to the cell. And then incubated for 30 minutes, after that the cells centrifuged at 5,000 rpm for 3-4 minutes. The supernatant was discarded, and the cells resuspended by adding $200 \mu \mathrm{l}$ of PBS and centrifuged as above, this process was repeated 3 times for complete cells washing by PBS, the cells were collected by centrifugation as above. Cell dehydration was carried out by using serial dilutions of ethanol $(30 \%, 50 \%, 70 \%, 80 \%$, $90 \%$ and $100 \%$ ), the cells were resuspended by $1 \mathrm{ml}$ of $30 \%$ ethanol and incubated at room temperature for 1 minute then centrifuged, the supernatant was discarded, and these steps were repeated for each of the ethanol dilutions. The cells were kept in $100 \%$ ethanol until coated and examined.

\section{Cell lysate preparation and expression analysis}

The production isolate from the entire medium was harvested by centrifugation at 5,000 rpm for 20 minutes at $4{ }^{\circ} \mathrm{C}$ and the cells pellet were resuspended by a lysis buffer. In this study, the lysis buffer was consisted of $50 \mathrm{mM}$ Sodium phosphate $\left(\mathrm{NaH}_{2} \mathrm{PO}_{4}\right) \mathrm{PH}=8,300 \mathrm{mM} \mathrm{NaCl}, 8 \mathrm{M}$ Urea and $100 \mu \mathrm{l}$ of $(0.1 \%)$ lysozyme for each $\mathrm{ml}$ of the lysis buffer, in addition to $1 \mathrm{mM}$ of PMSF and $1 \mu \mathrm{l}$ of $\beta$-mercaptoethanols were added. The cells suspension was shacked and vortexed then incubated for 20 minutes at $37^{\circ} \mathrm{C}$ after that the cells homogenized by using the sonication burst for $15 \mathrm{~min}$ at $4^{\circ} \mathrm{C}$, and $60 \mathrm{~Hz}$ intensity, then the samples were centrifuged at 5,000 rpm for 15 min to obtain clear lysate and stored at -20 until analyzed on $12 \%$ SDS-PAGE or submitted to the protein purification processes. ${ }^{[13]}$

\section{Recombinant protein purification by affinity chromatog- raphy}

The expressed protein was primarily purified from the whole cell lysate by using His Link ${ }^{\mathrm{TM}}$ Protein Purification $\operatorname{Resin}^{[14]}$ (affinity chromatography). Batch purification procedure was performed as described by the supplying company (with a little modification). The binding and washing buffer used for HisLink ${ }^{\mathrm{TM}}$ Protein Purification consisted of $50 \mathrm{mM}$ phosphate buffer $\left(\mathrm{NaH}_{2} \mathrm{PO}_{4}\right) \mathrm{PH}=8,300 \mathrm{mM} \mathrm{NaCl}$, $5 \mathrm{mM}$ Imidazole and Up to $8 \mathrm{M}$ Urea, while, the elution buffer contained the same component like binding and washing buffer in addition to $250 \mathrm{mM}$ Imidazole. Then, the product of the HisLink ${ }^{\mathrm{TM}}$ Protein Purification system was dialyzed using dialysis tube as described by Santos et al. ${ }^{[15]}$ The recombinant protein was dialyzed in a buffer consisted of $50 \mathrm{mM}$ phosphate buffer $\left(\mathrm{NaH}_{2} \mathrm{PO}_{4}\right), 100 \mathrm{mM} \mathrm{NaCl}, 0.1$ $\mathrm{Mm}$ EDTA and $10 \% \mathrm{v} / \mathrm{v}$ glycerol $(\mathrm{PH}=8)$. The volume of the dialysis buffer was primarily equal to $10 \mathrm{X}$ of sample volume (10 $\mathrm{ml}$ of sample was dialyzed in a $100 \mathrm{ml}$ of dialysate). This process was carried out at $4^{\circ} \mathrm{C}$ for 4 hours, and then the sample was dialyzed in a buffer volume equal to $100 \mathrm{X}$, for overnight at $4^{\circ} \mathrm{C}$.

\section{Proteolytic cleavage of recombinant protein with En-} terokinase enzyme

In order to get the target protein (hPTH) without other parts of the production recombinant fused protein, the dialyzed recombinant protein was digested by $(0.01 \mathrm{U} / \mu \mathrm{l})$ concentration of Enterokinase enzyme. The reaction tube was prepared according to the recommendation of supplying company. ${ }^{[16]}$

\section{Purification of hPTH by ion exchange chromatography}

To purify the target protein (hPTH), two kinds of ion exchange chromatography columns were used:

(1) Purification by DEAE Sepharose column (Anion exchange chromatography)

A prepacked HiTrap DEAE sepharose fast flow columns which were supplied from (GE Health care), was equilibrated with 3-5 column volumes of $20 \mathrm{mM}$ Tris- $\mathrm{HCl} \mathrm{pH} 8.0$, at flow rate of 3-4 $\mathrm{ml} / \mathrm{min}$. then, the product of Enterokinase proteolytic cleavage was loaded on the DEAE sepharose column directly (after 16 hours of incubation of the whole recombinant fused protein with Enterokinase). Then, the penetration from the DEAE Sepharose column was collected, and in order to elute all the undesirable proteins and to re-use the column, a washing solution $(20 \mathrm{mM}$ Tris- $\mathrm{HCl} \mathrm{PH}=8$ and $1 \mathrm{M} \mathrm{NaCl}$ ) was used to wash the column with 3-5 column volume and then with 3-5 column volume of equilibration solution.

(2) Purification by SP Sepharose Column (Cation Exchange Chromatography)

After collection of the penetration from DEAE sepharose column, the penetration was adapted to $\mathrm{pH} 6.3$, and loaded on a SP Sepharose FF column. Before loading, the SP column washed with 3-5 column volume of SP equilibrated buffer (20 mM of $\mathrm{NaH}_{2} \mathrm{PO}_{4}, \mathrm{PH}=6.3$ ). The SP column was washed with the buffer consisted of $80 \%$ of SP equilibrated buffer and $20 \%$ of buffer $\mathrm{E}\left(20 \mathrm{mM} \mathrm{NaH}_{2} \mathrm{PO}_{4}\right.$ and $500 \mathrm{mM}$ $\mathrm{NaCl}, \mathrm{pH} 6.3$ ) to remove simple washing proteins, the target protein was eluted by $80 \%$ buffer E mixed with $20 \%$ of SP equilibrated buffer. 


\section{Recombinant human Parathyroid Hormone Enzyme Im- munoassay}

Recombinant human Parathyroid Hormone Enzyme Immunoassay was carried out using kit order NO. EQ 64219601. (EUROIMMUN AG) Germany and the procedure used as in the manufacturer's instruction. The standard curve was prepared from the data produced from the calibrator with gradient Intact PTH (1-84) concentration on the $\mathrm{x}$ axis vs. absorbance on the $y$ axis, and then the concentration of the sample was calculated.

\section{HPLC column analysis for hPTH}

RP-HPLC analysis was performed for intact rhPTH and standard hPTH (Parathormon) (Novoprotein, USA) in the central lab. of Department of Chemistry College of Science in AlMustansiriya University. By injection of $20 \mu \mathrm{l}$ from each compound in the HPLC apparatus and HPLC chromatogram for each compound was performed by RP-HPLC analysis using solution consisted of $35 \%$ Acetonitrile and $65 \%$ Distell water with a flow rate of about (1.2) $\mathrm{ml} / \mathrm{min}$. Sol.

\section{The produced hPTH Haemolysis assay}

In order to study the haemolysis effect of the produced hPTH on the human RBC, the procedure of Laloy et al. ${ }^{[17]}$ was carried out with a slight modification. In the current study, the blood mixture prepared by mixing of $38 \mathrm{ml}$ of Ringer solution with $2 \mathrm{ml}$ of blood anticoagulated by EDTA and the positive control was $2 \mathrm{ml}$ of blood and SDS solution mixture, while, the negative control was blood mixed with Ringer solution. Different conc. of produced hPTH (10-1,200 $\mu \mathrm{g} / \mathrm{ml})$ was placed in the test tubes and the volume for each concentration was completed to $2 \mathrm{ml}$ with the blood mixture. Then the test tubes were incubated at $37^{\circ} \mathrm{C}$ for $1-2$ hours and all the solutions were centrifuged in $5,000 \mathrm{rpm}$ for $10 \mathrm{~min}$. the absorbance for the supernatant were measured at OD $405 \mathrm{~nm}$ to calculate the percent of haemolysis when the positive and negative control induce $100 \%$ and $0 \%$ of RBC haemolysis respectively.

\section{Bioactivity assay for the intact rhPTH}

The biological activity of the intact rhPTH and standard rhPTH (1-84) was carried out by calculation of the IC50 value for both the produced and the standard hormone on the MCF-7 breast cancer cell line using cAMP-Glo ${ }^{\mathrm{TM}}$ Assay kit, V1501 (Promega) and the test was done for the produced and standard hormones in CENAR center for natural product research and drug discovery, university of Malaya in Malaysia.

\section{RESUltS}

Expression of recombinant intact human Parathyroid hormone by BL21 (DE3) cells

As shown in Figures 1 and 2, in order to get an expression for the recombinant human parathyroid hormone (hPTH), cloning isolate was grown in LB broth media and when the OD.600 nm for the bacterial growth was reached to 1.1 the production was induced by the addition of IPTG. The expressed isolate was cleared by the examination under light microscope and scanning electron microscope which gave more definite form for the cloning isolate. The total protein concentration for the cell lysate of the production isolate was about $53 \mu \mathrm{g} / \mathrm{ml}$ while the protein concentration for the bacterial isolate before induction (addition of IPTG) was $42 \mu \mathrm{g} / \mathrm{ml}$.

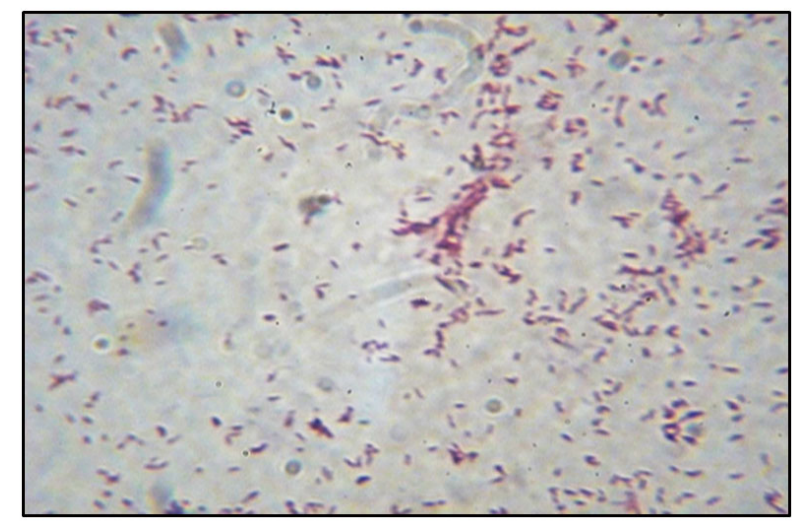

Figure 1. Light microscope examination of cloning isolate after staining it with gram stain as observed under $100 \mathrm{X}$ magnification of oil immersion microscope

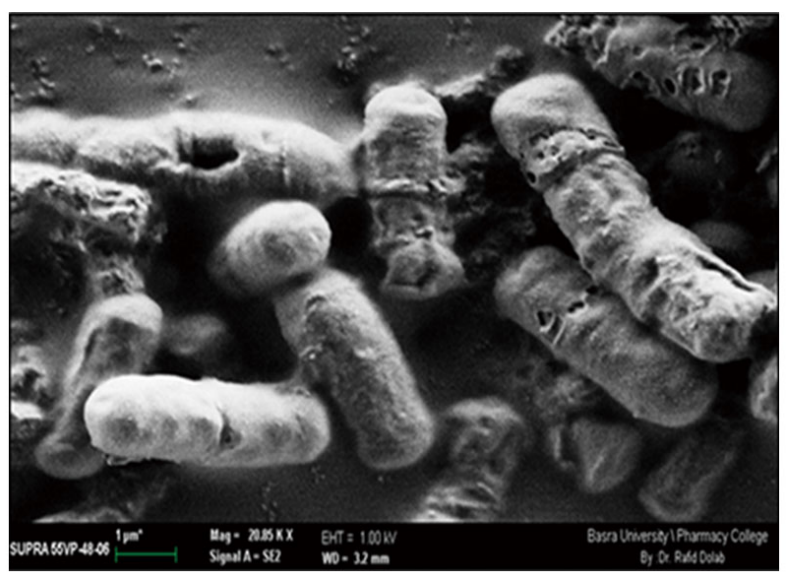

Figure 2. The scanning electron microscope examination of cloning isolate

As shown in Figures 3 and 4 which display all the amino acids sequencing of the fused protein, the $15 \%$ SDS PAGE 
electrophoresis was done for the whole cell lysate of the expression isolate and the band of the expected protein (fused protein of Thioredoxin - 6 Histidine tag -rhPTH with a molecular weight of about $26.4 \mathrm{kD}$, as calculated from the molecular weight for each individual protein in that fused protein).

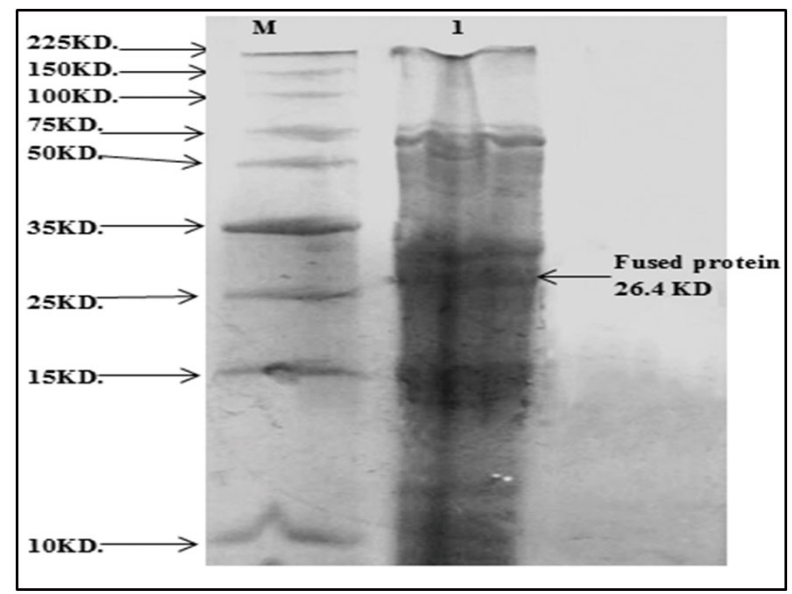

Figure 3. The 15\% SDS PAGE electrophoresis for (A) cell lysate of cloning isolates induced by IPTG, the lane M represent the protein marker and lane 1 was the cloning cell lysate

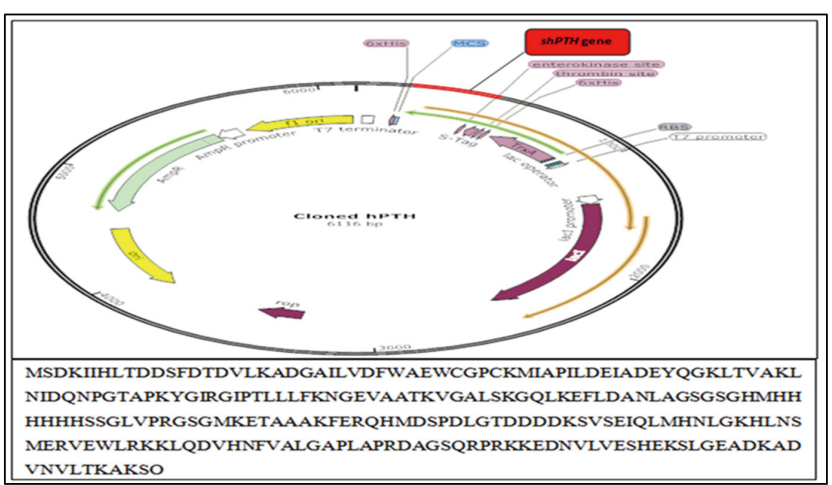

Figure 4. Recombinant pET32a-shPTH vector showing all parts of fused gene (Trx A, S-tag, 6xHis, Enterokinase and hPTH) gene which form the fused protein after translation. The sequence of fused protein was written in the Figure and each litter represents one amino acid, the fused protein is composed of 242 amino acids with a molecular weight of about $26.4 \mathrm{kD}$

\section{Purification of fusion protein (Trx.-6His.-hPTH) by affinity chromatography}

As shown in Figure 5, the preparation of cell lysate from cloning isolate which induced for recombinant fusion protein production, the later was purified primarily by affinity chromatography by using HisLink ${ }^{\mathrm{TM}}$ Protein Purification Resin Published by Sciedu Press
(Ni chelating resin), a few of the fusion protein was got by washing buffer and the rest fusion protein was eluted with elution buffer with $250 \mathrm{mM}$ Imidazole.

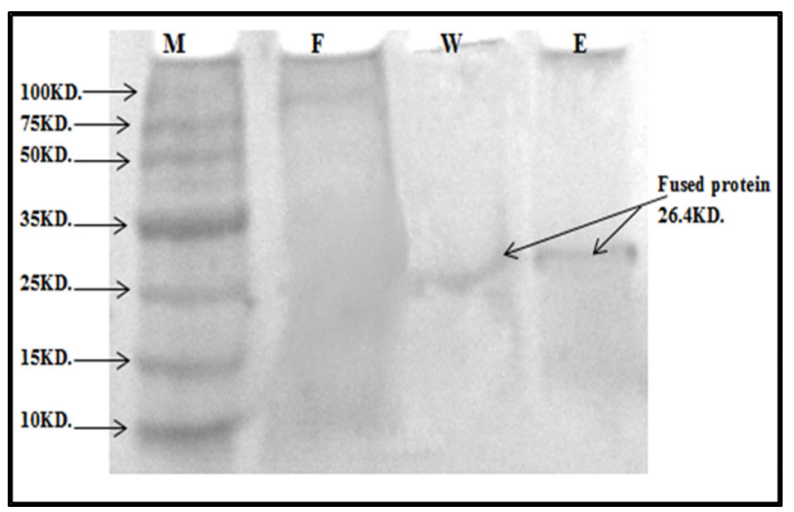

Figure 5. The 15\% SDS PAGE electrophoresis for affinity chromatography products for fusion protein at which lane $\mathrm{M}$ represent the protein marker, lane $\mathrm{F}$ was the flow through lane $\mathrm{W}$ was the washing of affinity column and lane $\mathrm{E}$ was the elution of the column

\section{Proteolysis of fusion protein by Enterokinase enzyme}

As shown in Figure 6, in order to obtain the target protein (recombinant intact human parathyroid hormone) the fused protein was digested with Enterokinase enzyme which recognizes the sequence [(Asp) 4-Lys] and cleaves the fusion proteins after the lysine residue.

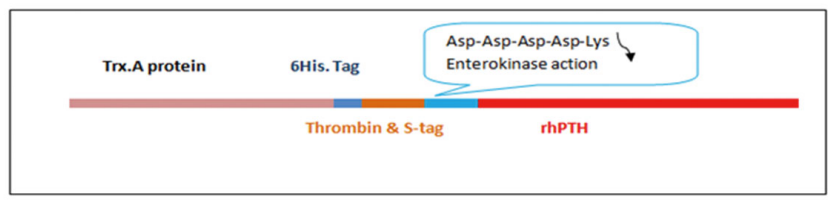

Figure 6. Enterokinase enzyme site of action

\section{Purification of rhPTH by Ion Exchange Chromatogra- phy}

To obtain the purified recombinant protein, two types of ion exchange column was used:

\section{(1) DEAE Sepharose FF Column}

All the Enterokinase digestion mixtures were loaded on DEAE Sepharose column. rhPTH was penetrated through the column, whereas, the Enterokinase, the tag and uncleaved His6-Trx-hPTH were retained on the column. So, the enzymatic cleavage action of Enterokinase was terminated. And the Figure 7 shows the SDS PAGE electrophoresis for DEAE Sepharose column product, the rhPTH appeared in expected band at $9.4 \mathrm{kD}$. 


\section{(2) SP Sepharose FF Column}

As shown in Figure 7, the penetrated product of DEAE Sepharose column was converted to a little acidic buffer with $\mathrm{PH}=6.3$ and loaded in Cation exchange column (SP Sepharose FF) which was utilized for further purified of the recombinant protein. The latter was washed by the $\mathrm{NaH}_{2} \mathrm{PO}_{4}$ buffer with $100 \mathrm{Mm} \mathrm{NaCl}$ and eluted with the same buffer with $400 \mathrm{mM} \mathrm{NaCl}$ and that lead to concentrate the protein from $85 \mathrm{pg} / \mathrm{ml}$ to $225 \mathrm{pg} / \mathrm{ml}$ and the eluted protein was examined by measuring the absorbance at $280 \mathrm{~nm}$ which give a highest absorbance of $(4.4 \mathrm{~nm})$ which detected by SDS PAGE electrophoresis that show the rhPTH eluted from SP column.

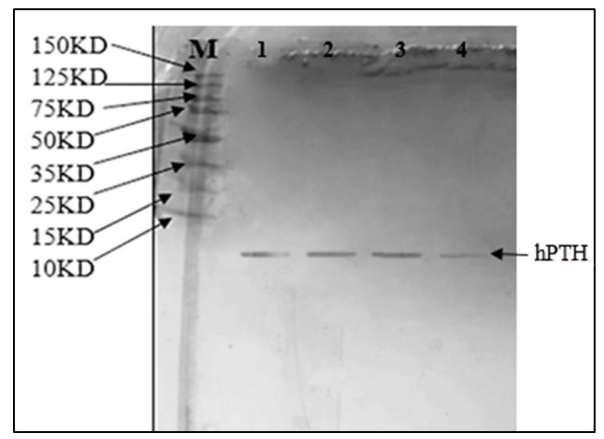

Figure 7. 15\% SDS PAGE electrophoresis for DEAE Sepharose and SP Sepharose column Products. Lane M represent protein marker and lane 1, 2 represent DEAE Sepharose column flow through and lane 3, 4 represent the eluted protein from SP Sepharose all the bands appeared in the expected molecular weight of $9.4 \mathrm{kD}$.

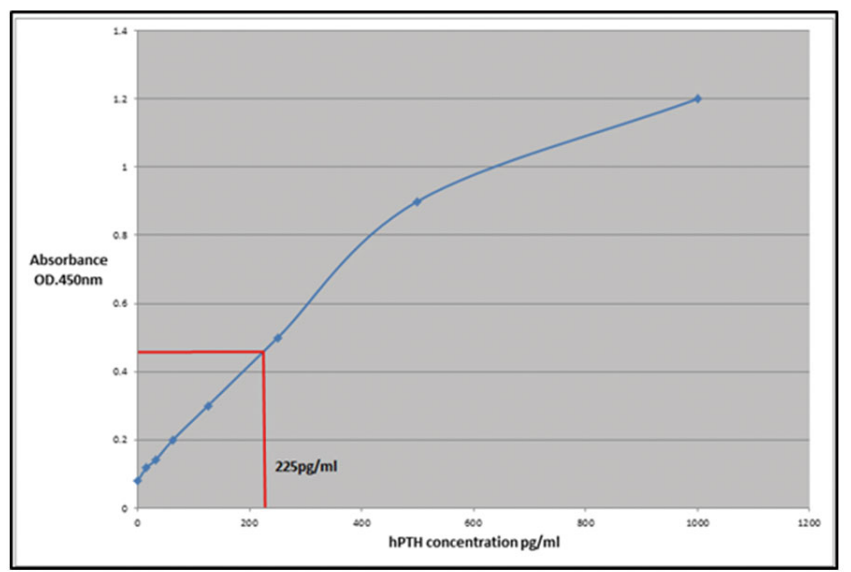

Figure 8. The hPTH standard curve of hPTH ELISA test

\section{ELISA immunoassay for recombinant hPTH}

As shown in Figure 8, the ELISA test for recombinant hPTH detected directly the presence of the recombinant hormone by binding of recombinant hormone with specific antibody, and quantified the concentration of the hormone after two ion exchange columns purification processes it was about $225 \mathrm{pg} / \mathrm{ml}$. which identified by the parathyroid hormone standard curve and this result comes as additional confirmatory result for expression of shPTH gene in our cloning isolate which was primarily detected using Real Time PCR as described by (Al-badran \& Abdul-jabbar). ${ }^{[18]}$

\section{HPLC analysis for rhPTH}

As shown in Figure 9, RP-HPLC analysis for intact rhPTH and standard rhPTH (1-84) show a high degree of similarity in hPTH peaks in a retention time about 45 minutes which represents the HPLC peaks for standard and the produced rhPTH.

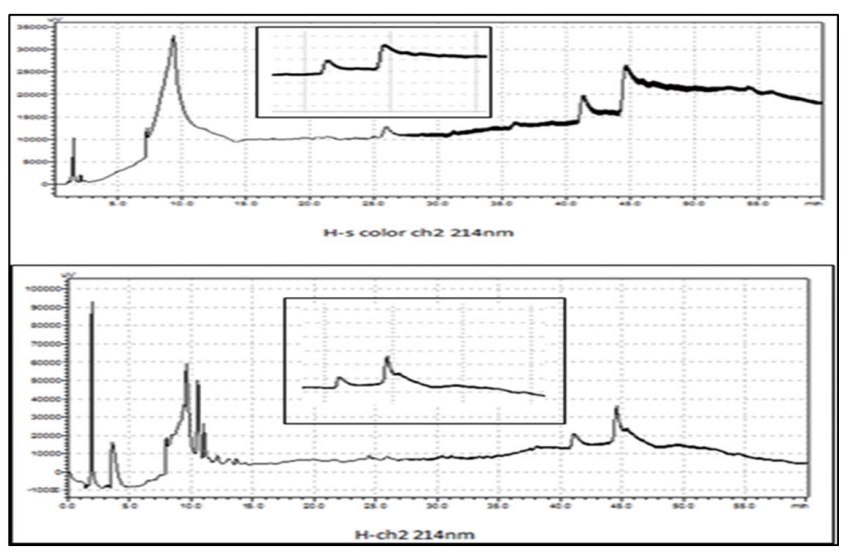

Figure 9. The HPLC peaks for standard above and produced rhPTH below

\section{The produced hPTH Haemolysis assay}

As shown in the Figures 10, 11 and 12, the produced hPTH haemolysis assay shows the ability of the produced hormone to partially haemolyze the RBC in a high concentration.

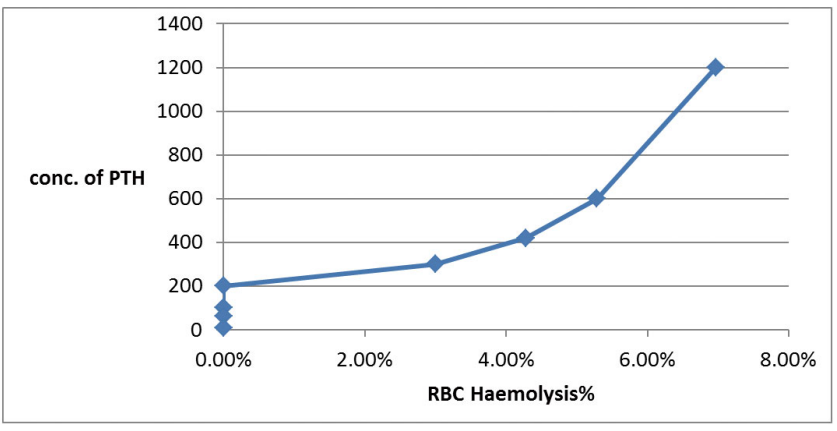

Figure 10. The produced hPTH (RBC. Haemolysis) assay 


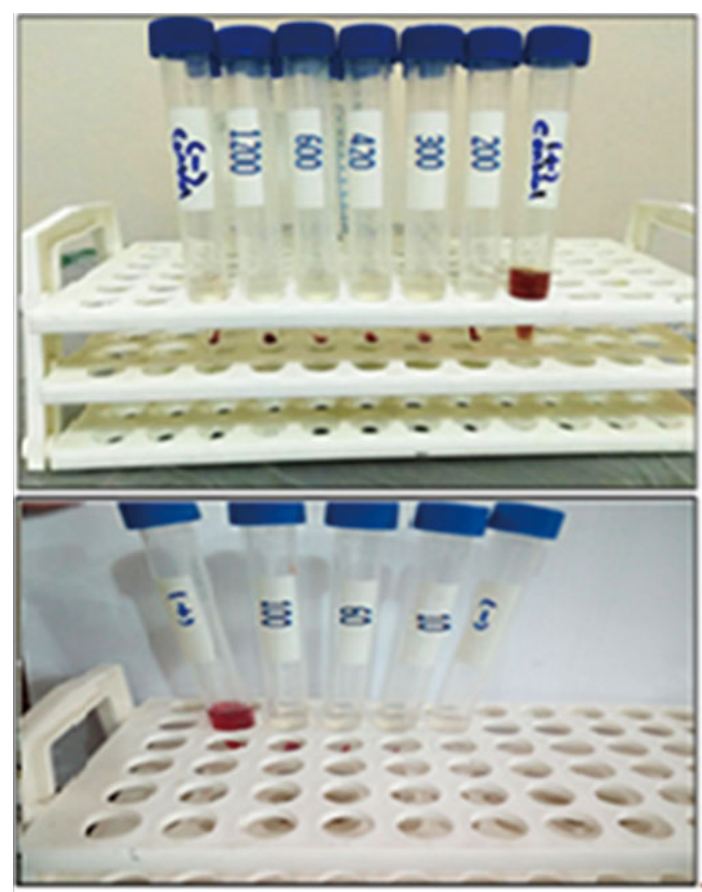

Figure 11. The haemolysis assay tubes after centrifugation
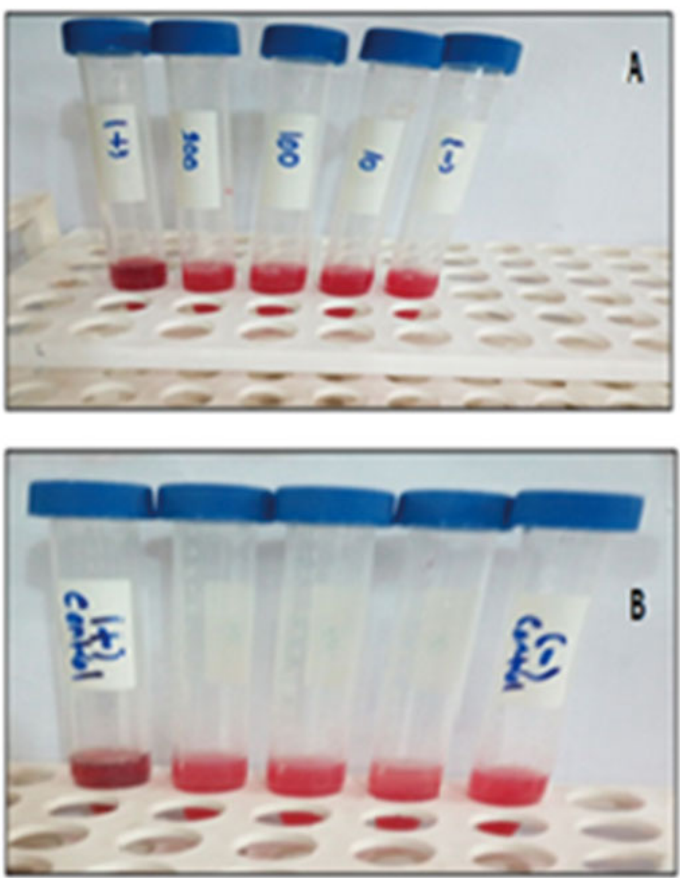

Figure 12. A. The non-haemolysis produced hPTH concentrations. B. The partially hemolysis produced $\mathrm{hPTH}$ concentrations. Each with positive and negative control.

\section{Bioactivity assay for the intact rhPTH}

As shown in the Table 1 and Figure 13, the IC50 for the compounds and curves used to calculate this values which indicate that the produced and standard rhPTH both had a Published by Sciedu Press biological activity on the MCF-7 Breast cancer cell, and the statistical analysis for the IC50 values for all compounds using two way ANOVA showed no significant difference between them.

Table 1. The IC50 value for rhPTH

\begin{tabular}{ll}
\hline Compounds & IC50 $(\boldsymbol{\mu g} / \mathbf{m l})$ \\
\hline Standard rhPTH & 84.4 \\
Intact rhPTH sample1 & 75.7 \\
sample2 & 70 \\
\hline
\end{tabular}

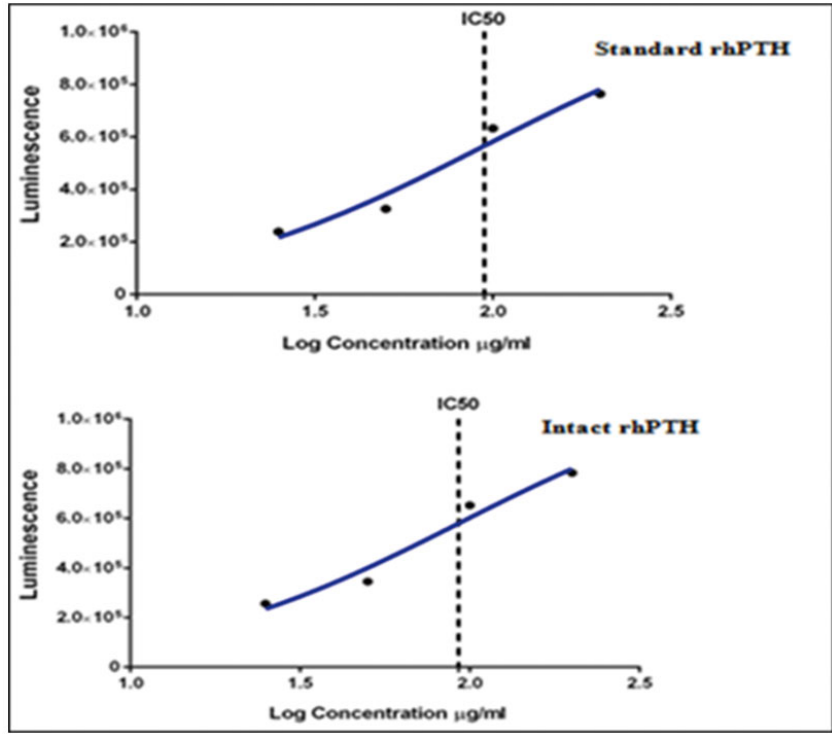

Figure 13. The line curves for hPTH bioactivity analysis and measuring IC50

\section{Discussion}

The expression of recombinant human Parathyroid hormone was carried out by growing the transformed isolate BL21 (DE3) in a production media and because it's a lysogen of $\lambda$ DE3 it carries a chromosomal copy of the T7 RNA polymerase gene under control of the lacUV5 promoter such strains are suitable for production of protein from target genes cloned in $\mathrm{pET}$ vectors or other protein under the control of T7 promoter. ${ }^{[19]}$ Also, IPTG (Isopropyl $\beta$-D1-thiogalactopyranoside) was added. This compound is a molecular mimic of allolactose, a lactose metabolite, IPTG binds to the lac repressor and releases the tetrameric repressor from the lac operator and that triggers transcription of the lac operon, and it is therefore used to induce protein expression where the gene is under the control of the lac operator, ${ }^{[20]}$ that works to expression of T7 RNA Polymerase by genomic DNA which then bind to the $\mathrm{T} 7$ promoter for $h P T H$ gene expression.

Despite of the absence of the di Sulfur bond in our recombi- 
nant protein structure and expression of the target protein as a fusion protein with a Thioredoxin (it's a small disulphidecontaining proteins that serves as a general protein disulphide oxidoreductase with 109 aminoacid) regard as one of the most important system which successful in producing correctly folded and soluble heterologous proteins in the bacterial cytoplasm. ${ }^{[21,22]}$ The $\beta$-mercaptoethanol which is a reduction factor as well as the Urea with $8 \mathrm{M}$ concentration (a denaturing substance that can efficiently hydrolysis the inclusion bodies if present) was added to the cell lysis buffer because, it was first time to produce the target protein with thioredoxin in our lab and as a precautionary step, all these compounds were used, since all the additional solutions do not had effect on the recombinant protein structure and activity.

Immobilized metal affinity chromatography (IMAC) is a powerful purification technique that dependent on a molecule's affinity for certain metals fixed onto a chelating surface. For purification of our fused protein, a macro porous silica resin (modified to contain a high level of tetradentate-chelated nickel [ $>20 \mathrm{mmol} \mathrm{Ni/ml} \mathrm{settled} \mathrm{resin]} \mathrm{for} \mathrm{efficient} \mathrm{cap-}$ ture and purification of bacterially expressed polyhistidine proteins) were used and for highly through put of purified protein.

In the current study, the dialysis tube was used for two reasons primarily to eliminate all the bacterial proteins with a molecular weight below $14 \mathrm{kD}$. Molecular-weight cutoff (MWCO) limits of the dialysis tube used were suitable for partially purified the protein of interest with a molecular weight of $26.4 \mathrm{kD}$ that made it retain in the dialysis tube and not diffused in the buffer solution (dialysate). ${ }^{[23]}$ The second reason was to desalting and discarding any compound that used in the affinity chromatography and may be inhibit Enterokinase action, like Urea, Imidazole, and high concentration of $\mathrm{NaCl}$ as recommended by the enzyme production company. ${ }^{[16]}$ Also, the dialysis of the protein of interest in two times, as described above in the presence of glycerol and a concentration of EDTA that let any denatured protein -if present- effected by urea to renature (refolded) and retain its biological normal form again. ${ }^{[15]}$

Ion-exchange is a largely used system for separating biomolecules according to differences in ionic charge, in this study we used primarily a weak anion exchange column, the DEAE Sepharose column for terminating the action of Enterokinase enzyme, by separating the Parathyroid hormone (target protein) after proteolysis of fusion protein by Enterokinase from the non-proteolysis fusion protein and the fusion partner (TrxA-His. Tag) of the proteolysis protein as well as all the proteolysis reaction products, this was carried out depending on proteins PI and the surrounding PH. In this case, the PI of the fusion partner (TrxA-His. Tag), non-proteolysis fusion protein and PTH was about 5.4, 6.1 and 9 respectively as calculated by ExPASy ProtParam tool (which allows the calculation of numerous physical and chemical factors for a given protein including the theoretical PI, molecular weight, amino acid composition etc.), and 5.1 for Enterokinase enzyme, ${ }^{[24]}$ and the surrounding $\mathrm{PH}$ was about 8 that increase the negative charge for all proteins except the PTH which still have a positive charge because the surrounding PH below its PI. The negatively charged proteins bind tightly with the positively charged anion exchanger, while PTH do not bind with the same charged phase, therefore it's penetrate rapidly. Then the penetration protein was adapted to buffer with $\mathrm{PH}=6.5$ below the Parathyroid hormone PI that make it positively charged and can bind tightly with the strong cation exchange SP column then a linear gradient of increasing sodium chloride concentration method was used in washing and elution buffer to purify and elute the parathyroid hormone. ${ }^{[25,26]}$

In this study, as an alternative choice for amino acids sequencing test the standard and produced (intact) PTH underwent analysis by RP-HPLC, and HPLC chromatogram was performed using $214 \mathrm{~nm}$ UV spectrum, which was suitable UV spectrum with highly resolution and distinct peaks for many proteins and peptides like human and bovine Insulin, Fibrinogen and Aprotinin etc. ${ }^{[27,28]}$ Also the HPLC chromatogram for both the standard and produced hPTH showed the same main peaks at nearly the same retention time as shown in Figure 9, and the hPTH peaks in both samples are mostly appeared at a retention time of about 45 minutes, the peaks type mainly similar in both samples and they are also resemble to the human PTH (1-84) peaks which appeared in HPLC chromatogram for human serum sample analyzed by RP-HPLC using elution solution contain a gradient range of Acetonitril (CAN) which was reached to the $33 \%$ of the total elution solution components and it's near the Acetonitrile percent $(35 \%)$ that was used in HPLC analysis of this study. ${ }^{[29,30]}$ According to the ability of using the produced hPTH as a drug for treatment of severe bone osteoporosis for human that open the door for doing multiple test to checking its safety for human, one of the more important test is the studying of its effect on the human RBC. By doing the haemolysis assay for produced hormone which show the ability of the hormone to hydrolyze the human RBC at a high concentration while in a low concentration there is no haemolysis effect on the RBC that's because the hPTH regard as a major factor influencing red blood cell osmotic fragility. One of the causes of short erythrocyte life span in uremic patients is the increase in erythrocyte osmotic fragility due to high concentration of the 
circulating intact parathyroid hormone, the RBC incubated with high PTH level form a filamentous membrane extension that anchor RBC together, that's mean the RBCs are one of the target sit of PTH and the latter work by increase the Ca efflux inside the cell. ${ }^{[31]}$ And that also gave an evidence for the similarity between the circulating Parathyroid hormone which secreted in our body and the produced Parathyroid hormone which had the same amino acids as confirmed by HPLC results.

The biological activity for the produced rhPTH was detected on the MCF-7 breast cancer cell line by using cAMP-Glo assay kit and Forskolin as activator for increase cAMP production by MCF-7 breast cancer cell ${ }^{[32]}$ primarily there is no luminesces due to increase cAMP as the concentration of cAMP increases that's due to cAMP-Glo kit mechanism of action in it the CAMP binds to protein kinase A, and the regulatory subunits undergo a conformational change to release the catalytic subunits. Then the free catalytic subunits catalyze the transfer of the terminal phosphate of ATP to a pro- tein kinase A substrate, consuming ATP (which carrying the luminesce pigment) in the process. The level of remaining ATP is determined using the luciferase-based Kinase-GloR Reagent. While when the standard and produced hPTH were added the luminesces increase with increase the concentration of PTH, that's mean increase in the ATP and from these result we can suggest that the PTH had antagonist effect (decrease cAMP) on the same site of Forskolin action on the MCF-7 cell, also, the IC50 (which mean the concentration of the tested agent that inhibits the proliferation of the cancer cell population to $50 \%$ of the theoretically possible effect [absolute IC50] or maximum effect ${ }^{[33]}$ ) for both standard and produced PTH IC50 were calculated and there was no significant difference between the standard and produced PTH effect which mean that the produced PTH also had a biological activity.

\section{ACKNOWLEDGeMENTS}

The authors are grateful to the laboratory of Cell and Biotechnology Researches Unit.

\section{REFERENCES}

[1] Sekhon BS. Biopharmaceuticals: An overview. Thai Journal of Pharmaceutical Sciences. 2010; 34(1): 1-19. http://doi.org/10.100 7/978-94-017-0926-2_1

[2] Hwang I. Thyroid and parathyroid glands, Dep.of Physiology Faculty of medicine, University of Hong Kong; 2007.

[3] Borba VZC, Mañas NCP. The use of PTH in the treatment of osteoporosis. Arquivos Brasileiros de Endocrinologia E Metabologia. 2010; 54(2): 213-9. https://doi.org/10.1590/S0004-27302 010000200018

[4] Aslan D, Andersen MD, Gede LB, et al. Mechanisms for the bone anabolic effect of parathyroid hormone treatment in humans. Scandinavian J. Clin. Lab. Invest. 2012; 72(1): 14-22.

[5] Warden SJ, Komatsu DE, Rydberg J, et al. Recombinant human parathyroid hormone (PTH 1-34) and low-intensity pulsed ultrasound have contrasting additive effects during fracture healing. Bone. 2009; 44(3): 485-94. PMid:19071238. https ://doi .org/10.101 $6 / j$.bone. 2008.11 .007

[6] GE Healthcare, Recombinant Protein Purification Handbook. Methods. 2009; 41(7): 1-306.

[7] Young CL, Britton ZT, Robinson AS. Recombinant protein expression and purification: A comprehensive review of affinity tags and microbial applications. Biotechnology Journal. 2012; 7(5): 620-34. PMid:22442034. https://doi.org/10.1002/biot. 201100155

[8] Magdeldin S, Moser A. Affinity Chromatography: Principles and Applications. 2012 under CC BY 3.0 license. (C) The Authors.

[9] Lodish H, Berk A, Zipursky SL, et al. Molecular Cell Biology, 4th edition. New York: W. H. Freeman; 2000. ISBN-10: 0-7167-3136-3, 1.

[10] Novagen Competent cells. User Protocol TB009 Rev. H 0211JN @ EMD Chemicals Inc. 2011. 1-19.

[11] Waterborg JH, Matthews HR. The Lowry Method for Protein Quantitation. Proteins. 2000: 2-4.

Published by Sciedu Press
[12] Schädler S, Burkhardt C, Kappler A. Evaluation of Electron Microscopic Sample Preparation Methods and Imaging Techniques for Characterization of Cell-Mineral Aggregates. Geomicrobiology Journal. 2008; 25: 228-39. https ://doi .org/10 .1080/0149045080 2153462

[13] BIO-RAD Laboratories. Profinity TM IMAC Resins Instruction Manual. Proteins. 2000. Alfred Nobel Dr., Hercules, CA 94547 USA 510-741-1000.

[14] Promega. HisLink Protein Purification Resin Technical Bulletin \#TB327. U.S. Pat. Nos. 7,112,552 and 7,354,750, 2013.

[15] Santos CA, Beloti LL, Toledo MAS, et al. A novel protein refolding protocol for the solubilization and purification of recombinant peptidoglycan-associated lipoprotein from Xylella fastidiosa overexpressed in Escherichia coli. Protein Expression and Purification. 2012; 82(2): 284-9. PMid:22306742. https ://doi.org/10.101 6/j.pep. 2012.01.010

[16] Invitrogen Enterokinase $\operatorname{Max}^{\mathrm{TM}}\left(\mathrm{EKMax}^{\mathrm{TM}}\right)$. Catalog nos. E180-01, Version H, Invitrogen Corporation, USA; 2006.

[17] Laloy J, Minet V, Alpan L, et al. Impact of Silver Nanoparticles on Haemolysis, Platelet Function and Coagulation. Nanobiomedicine. 2014; 1: 1-9.

[18] Al-badran A, Abdul-jabbar RA. Construction of Synthetic Intact Human Parathyroid Hormone Gene and Testing the Transformation Efficiency and Expression of it in E. coli strains. American Scientific Research Journal for Engineering, Technology, and Sciences. 2017; 27: 12-24.

[19] Novagen.competent cells. User Protocol TB009 Rev. F 0104 C EMD Biosciences, Inc., 2004. 1-23.

[20] Agilent Technologies. pET System Vectors and Hosts. Revision B.0 (C) Agilent Technologies, Inc. 2015.

[21] LaVallie ER, McCoy JM. Gene fusion expression systems in Escherichia coli. Current Opinion in Biotechnology. 1995; 6(5): 501-6. https://doi.org/10.1016/0958-1669(95)80083-2 
[22] Novagen. 69015 pET-32a (+) DNA, (C) Merck KGaA, Darmstadt, Germany; 2014. 1-2.

[23] Haney P, Herting K, Smith S. Molecular weight cut-off (MWCO) specifications and rates of buffer exchange with Slide-A-Lyzer Dialysis Devices and Snakeskin Dialysis Tubing. Thermo Fischer Scientific. 2013; 4: 100 .

[24] Gasteiger E, Hoogland C, Gattiker A, et al. Protein Identification and Analysis Tools on the ExPASy Server. The Proteomics Protocols Handbook, Humana Press. 2005. 571-607.

[25] GE Healthcare, Instructions 56-1191-00 AF, Ion Exchange CM Sepharose Fast Flow DEAE Sepharose, Fast Flow Q Sepharose, Fast Flow SP Sepharose. Published by GE Healthcare AB, a General Electric Company. 2006. Available from: www.gehealthcare.com /protein-purification

[26] GE Healthcare Bio-sciences. Ion exchange columns and media Selection guide - Ion Exchange Media. Selection Guide. 2011. 2-3.

[27] Aguilar MI, Højrup P. Methods In Molecular Biology TM Proteolytic Peptide Mapping Edited By HPLC Of Peptides and Proteins Methods and Protocols HPLC of Peptides and Proteins, 251, (c) Humana Press Inc., 2004. Totowa, NJ.
[28] Jupiter. Reversed Phase HPLC Solutions for Proteins and Peptides. Phenomenex, Inc. 2008.

[29] D'Amour P, Brossard JH, Rousseau L, et al. Structure of non-(184) PTH fragments secreted by parathyroid glands in primary and secondary hyperparathyroidism. Kidney International. 2005; 68(3): 998-1007. PMid:16105030. https ://doi.org/10.1111/j.1523 $-1755.2005 .00493 . \mathrm{x}$

[30] Vieira JGH, Kunii I, Nishida S. Evolution of PTH assays. Arquivos Brasileiros de Endocrinologia E Metabologia. 2006; 50(4): 621-7. https://doi.org/10.1590/S0004-27302006000400007

[31] Massry SG, Nishizawa Y, Morii H. Calcium in Internal Medicine. Springer Science \& Business Media. 2012: 504.

[32] Dessauer BT, Nguyen CW. Relaxin Stimulates cAMP Production in MCF-7 Cells upon Overexpression of Type V AdenylylCyclase. Ann N Y Acad Sci. 2005; 1041(5): 296-9. PMid:15956721. http: //doi.org/10.1038/jid.2014.371

[33] Nevozhay D. Cheburator user manual version 1.2.0, (2014) 16. http://doi.org/10.1007/SpringerReference_28001 